\title{
2006-371: AN INTEGRATED APPROACH TO A ONE-SEMESTER SHIP DESIGN EXPERIENCE AT USCGA
}

\section{Todd Taylor, U.S. Coast Guard Academy}

\section{Kurt Colella, U.S. Coast Guard Academy}

CAPT Colella joined the USCGA faculty in 1988. He earned his B.S. in Ocean Engineering from USCGA in 1981. He received MS degrees in Mechanical Engineering and Naval Architecture and Marine Engineering from Massachusetts Institute of Technology in 1985. In 1997 he earned his Ph.D. in Mechanical Engineering from the University of Connecticut. He has been a registered Professional Engineer in the State of New Hampshire since 1991. At the Coast Guard Academy, he has taught a variety of courses in ship design, fluid mechanics, thermodynamics and thermal systems, aerodynamics, strength of materials, differential equations, engineering design and calculus. He has acted as faculty advisor for numerous senior design projects and directed study projects in both Naval Architecture and Marine Engineering and Mechanical Engineering. In 2000, CAPT Colella was selected as the Coast Guard Engineer of the Year for outstanding service and contributions to his profession.

\section{William Simpson Jr., U.S. Coast Guard Academy}

Professor Simpson joined the faculty of the Engineering Department at the Coast Guard Academy for the second time in the fall of 2000. He has a Ph.D. in Aerospace Engineering form the University of Maryland, a Masters in Naval Architecture and Marine Engineering form Massachusetts Institute of Technology, and a Bachelor of Science form the U. S. Coast Guard Academy. He is a registered Professional Engineer in the State of Connecticut. He previously taught at the Coast Guard Academy from 1974 to 1978 while serving on active duty in the Coast Guard. He retired form the Coast Guard in 1992 at the rank of Captain having had assignments in Marine Safety, Naval Engineering, Acquisition, and Research and Development. His last assignment on active duty was as Commanding Officer of the Coast Guard Research and Development Center in Groton, CT. After retirement from active duty, prior to coming to the Coast Guard Academy faculty, he worked as an independent naval architect. 


\title{
An Integrated Approach to a One-Semester Ship Design Experience at USCGA
}

\begin{abstract}
At the United States Coast Guard Academy, the transition from general education and general engineering -- to courses specific to the Naval Architecture and Marine Engineering (N\&AME) major -- occurs in spring of the junior year. As such, the time available for a developmental (or incremental) approach to the design of a ship is limited. As a cornerstone to a strong designbased NA\&ME education, the faculty has adopted an integrated one-semester ship design experience involving three courses. While the courses remain separate entities with three instructors, different meeting times, and largely non-overlapping content, the student experience is one of continuity and integration between the subject areas. The integrated approach is presented here with an emphasis on faculty cooperation and communication, as well as outside interest and participation from field design offices. A case study is presented to demonstrate the faculty coordination necessary to replace the traditional incremental approach to design with an integrated, comprehensive, one-semester experience. The benefits of this approach are discussed as well as the resources needed to sustain it in the long term.
\end{abstract}

\section{The USCGA Challenge}

The United States Coast Guard Academy (USCGA) provides the U. S. Coast Guard (USCG) with approximately 190 new Coast Guard officers each year. Each graduate earns both a commission (as Ensign, USCG) and a Bachelor of Science degree in one of eight academic majors. USCGA is one of four federal service academies and as such is focused on the academic, military and physical development of young men and women as leaders in service to our nation.

The education and training program at USCGA is four years in duration and upon completion, each graduate is obligated to five years of military service. Approximately $80 \%$ of the graduating class report to Coast Guard Cutters throughout the world and the remaining 20\% are employed in flight training or marine safety and environmental readiness/response duties. They are paid on a common scale based on service longevity and a performance-based promotion system.

A typical cadet day at USCGA involves academics, leadership and military training, and some sort of athletic activity (NCAA division III or intramural). At least once each semester, each cadet is required to participate in an outside community service project either individually or as a group. All cadets must complete the academic requirements for their chosen major while participating in the equivalent of two full sports seasons (in addition to 7 semesters of physical education), in parallel with a 200 week training program. Of the eight academic majors, four are engineering and others include operations research, marine and environmental science, management and government. The academic workday runs from 0600-1540 and 2000-2200 (late lights beyond 2200 permitted with excusal). The general education requirement ("core curriculum") for all cadets involves 17 courses and 57 credit hours. The ABET-accredited Naval 
Architecture and Marine Engineering (NA\&ME) major, including the core curriculum, involves 144.5 credit hours and culminates in a comprehensive ship design project.

The environment described herein is a time-critical, pressure-packed experience that requires solid time management and task prioritization skills on the part of each cadet. These challenges are exacerbated for those in the NA\&ME major by the wide scope of content and huge array of analytical capabilities that each cadet must master. In addition, the capstone design experience involves the conceptual design and integration of a ship system which is inherently complex and highly sensitive to even the smallest alteration in operational requirements.

In order to meet the needs of the service and provide a high quality capstone design experience, the NA\&ME faculty at USCGA have adopted an approach that integrates high-end senior level design courses into a carefully choreographed progression that:

- provides the necessary tools (principles and practice) to conduct high quality design work in a "just in time" way

- addresses a single comprehensive design problem of direct relevance to the Coast Guard and the Department of Homeland Security.

- focuses on written and oral communication

- relies heavily on both student and faculty teamwork and strategic planning

- engages outside constituents as consultants, guest speakers and professional mentors

- exposes students to, and involves them in professional society activity

\section{The Ship Design Assignment}

Each fall the 1/c (senior) NA\&ME students carry out a semester-long design of a USCG cutter in a design team of 4 students. The team is assigned a 4-cubicle suite of design stations within which the 4 designers face (and can see) each other at all times. This team occupies this design suite for the entire semester. One member of the team is designated as the "team leader" to facilitate communication with the "project manager" (the instructor).

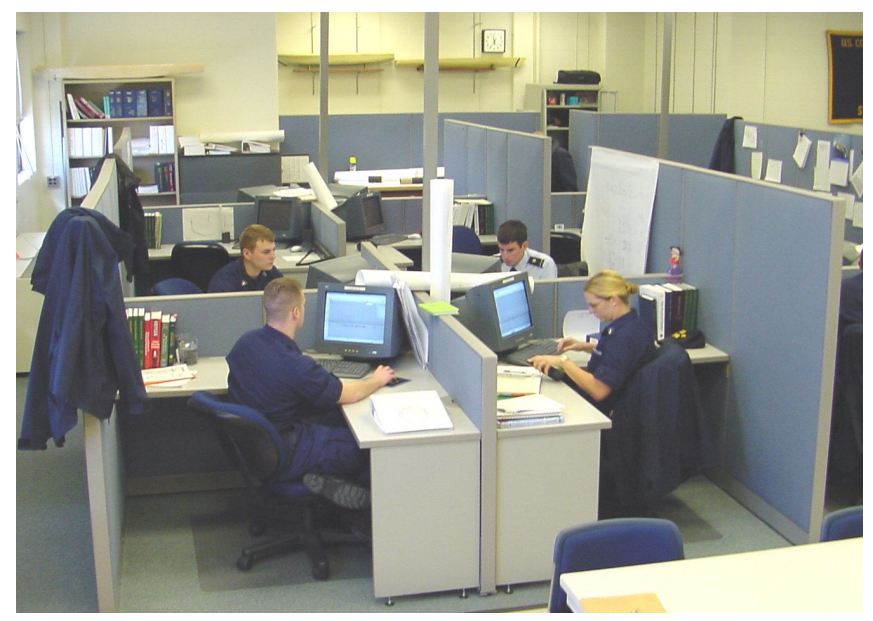

Figure 1: USCGA "Design Suite” for each cadet design team. 
The ship selected for design varies by year and typically is a vessel appropriate to one or all of the USCG missions including drug interdiction, alien migrant interdiction, search and rescue, aids to navigation, environmental protection, and homeland security. Selection of such a vessel generates significant student interest, as all cadets will one day serve at least one multi-year "tour" on, or in support of an operational Coast Guard cutter.

Since the early 1990's, the USCG has been in the midst of its most significant recapitalization and asset acquisition project in its 200+-year maritime history-the Integrated Deepwater System project. A significant part of this program is the redesign and alteration of existing ships and the design and building of new classes of vessels. The performance-based specifications for these vessels involve an all-encompassing requirement to be interoperable with air (manned and unmanned) assets, networked information systems, and other vessels of the USCG and U. S. Navy. Choosing cadet ship design projects that parallel, and are concurrent with, the design and build efforts of USCG contractors has made the NA\&ME design experience one of relevance and importance to the cadets. While the choice of real and "yet-to-be-designed" vessels often makes the design process a particular challenge for the faculty and students, the payoff in student interest and project relevancy far outweighs the increased unpredictability and occasional accompanying frustration.

\section{USCGA Approach to Ship Design}

Ship design is traditionally broken down into four stages: feasibility or conceptual design, preliminary design, contract design, and detail design. In the context of a one-semester undergraduate ship design, the level of refinement necessary for contract design - such that a contractor might be expected to be able to bid - and detailed design is generally beyond the knowledge and time constraints faced by our students. Thus, the USCGA ship design process is a combination of conceptual design and preliminary design. The end result of the design process consists of a hull shape, tow-tank model resistance prediction, ship motions ("seakeeping") evaluation, power estimate, propulsion plant, electrical power plant, internal arrangements, structural design, damaged stability assessment, superstructure layout, propellers, and shafting (See Figures 2 and 3 for Computer-Aided Design (CAD) renderings that all cadet design teams complete as a physical representation of their significant design and analysis accomplishments). Additional studies in the follow-on semester involve the designing of an HVAC system, several piping systems, an economic analysis, and a crewing study. The follow-on semester also includes consolidation of the designed ship attributes in a formal presentation to NA\&ME professionals and to non-academic CG stake holders.

The four stages of ship design were conceived to make up a "design spiral" (Evans, 1959²) where individual design tasks (hydrostatics, arrangements, powering, weight estimate, stability, etc) are arranged like the spokes of a wheel and each task is then considered in a largely serial fashion by following a circular path that intersects those spokes one by one (See Figure 4 from Taggart, $1980^{4}$ ). In fact, the path is not circular but rather a line that spirals inward (over a number of orbits around the center of the wheel) toward the center, or final design. Generally, conceptual design is at the outside of the spiral while detail design is assumed to make up the final, innermost trips around the center. By the nature of such a model, the individual steps in design can be argued to be somewhat independent of each other, sometimes lending each task to 
treatment by individual designers or teams with possibly limited communication or integration with those tasks that come before and after them.

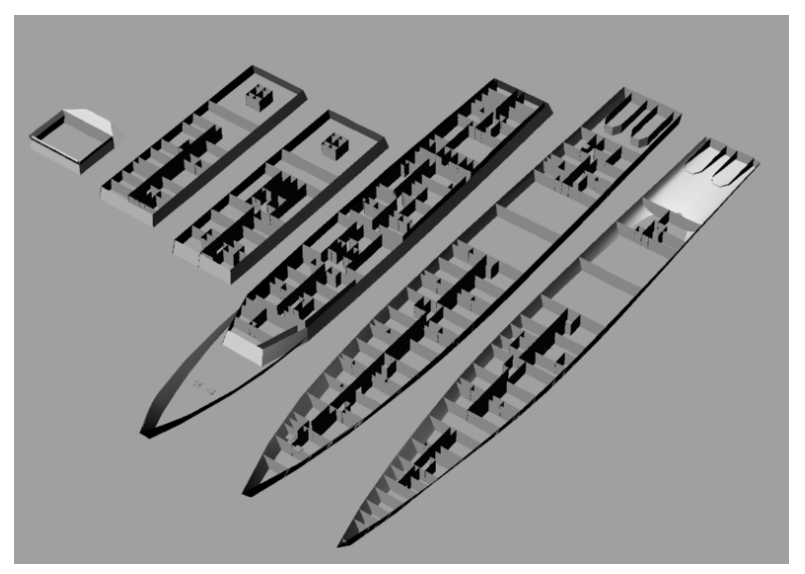

Figure 2: Student CAD representation of their team-designed proposal for the USCG Fast Response Cutter (WPC).

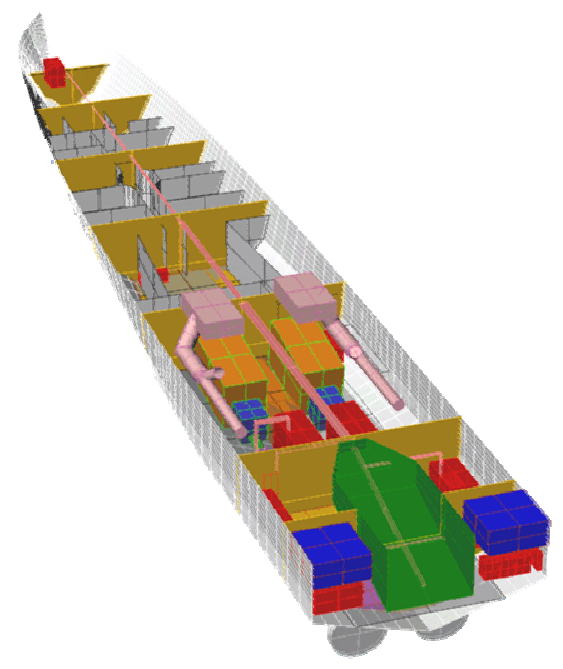

Figure 3: Student CAD representation showing all of the systems, powerplant, tankage, and arrangements designed during a one-semester ship design of a proposed USCG Fast Response Cutter (WPC). 


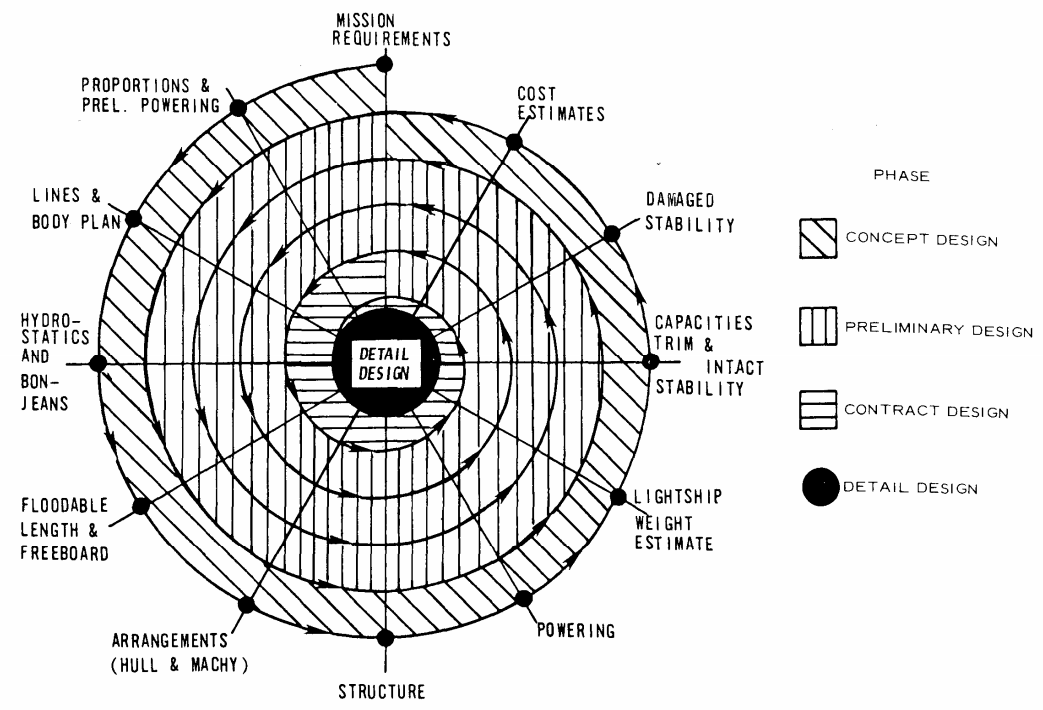

Figure 4: The Design Spiral (from Taggart, 19804)

The design spiral formulation is based on a serial approach to design tasks, with the decisions during a particular $360^{\circ}$ trip around the spiral being made based on incomplete information because the final design is assumed to be at the center - and compromise (Lamb, $2003^{3}$ ). Each successive trip around the spiral, though, affords the opportunity for iteration on the results of each design task as more and more unknowns are eliminated from the process. This iteration results in an acceptable solution, but it is often quite difficult to judge how good or bad the design is relative to other acceptable solutions.

A more modern model of ship design has recently been described (Lamb, 2003 ${ }^{3}$ ) as set-based design in which a set of designs that meet the requirements of the ship are simultaneously kept in consideration while particular unknowns (or all unknowns) are gradually fixed such that all but one design are identified as inferior solutions. Implicit in this process, though, is a relatively deep understanding and experience in ship design very near the beginning of the design process. The difficulty with the modern set-based design concept in an educational setting is the fact that design experience is non-existent and pre-requisite learning must take place. While this might sound obvious, the point is that unless students can learn nearly all pertinent design information in semesters prior to beginning their design project, the students necessarily must perform their design work with a "just-in-time" approach. Because students are learning the design applications of NA\&ME principles at the same time as they are executing their ship designs, students (and faculty) are forced to approach the one-semester design in much more of a serial fashion than a parallel set-based approach.

At USCGA, the courses directly related to NA\&ME and ship design are taken during the last three semesters. A single course - Principles of Naval Architecture (PNA) - is taken during spring of $2 / \mathrm{c}$ (junior) year. Content for this course consists of an introduction to the following fundamentals: NA\&ME nomenclature, ship hydrostatics, intact and damaged stability, hull strength, hydrodynamic resistance, and propulsion. Fall of the $1 / \mathrm{c}$ (senior) year is the semester- 
long integrated ship design experience. As such, students in the NA\&ME major have only the $P N A$ course before the students begin their actual ship design. Clearly, there is no way to successfully teach all of the necessary aspects of ship design during one course. Significant development and application of NA\&ME fundamentals must therefore occur in the concurrent Principles of Ship Design (PSD), Ship Structures (SS), and Ship Propulsion Design (SPD) courses (see table below for description of course formats). It is within the framework of these three classes that the semester-long ship design is carried out in a laboratory setting by design teams composed of 4 cadets, all of whom are enrolled in these same 3 courses.

\begin{tabular}{|c|c|c|}
\hline Course & Lecture Hours/Week & Lab Hours/Week \\
\hline $\begin{array}{c}\text { Principles of Ship Design } \\
\text { (PSD) }\end{array}$ & 3 & 3 \\
\hline $\begin{array}{c}\text { Ship Propulsion Design } \\
\text { (SPD) }\end{array}$ & 3 & 0 \\
\hline Ship Structures (SS) & 3 & 0 \\
\hline
\end{tabular}

Table 1: Fall semester design course formats

During the $P S D$, SS, and SPD courses the students quickly realize that the design of a ship is best described as a closely coupled process due to the strong interdependence (and often interference!) of the requirements of the different ship components. One example would be that transverse watertight bulkheads (or walls across the ship, see Figure 3) must be installed to enhance survivability and meet specified damaged stability requirements, but those bulkhead locations serve as significant inhibitors to effective use of internal volume of the ship during the arrangements process, particularly the placement of propulsion equipment. A second example would be that the arrangement of significant weights within the ship is driven somewhat by the fore-aft trim angle at which the ship will rest in the water, but the angle of the ship can vary significantly as one adjusts the outside shape of the ship to decrease the hydrodynamic resistance of the vessel. A third example is that the size and weight of the prime mover necessary for propulsion can require significant changes to the structural arrangement, bulkhead locations, and shape of the vessel, with resultant changes to the resistance and survivability of the ship as it is required to operate in a hostile environment (and this in turn also affects both the first and second examples!). As is typical of all design work these interdependent components frequently require trade-offs and compromises that the students must learn to execute. The demanding operational requirements for actual USCG ships provide many "real-world" imperatives for these trade-offs and compromises that are personal to our students because they know they will be operating and supporting these ships.

In the above examples, the authors have chosen some very real conflicts that exist during the design of a ship. Equally representative of real ship design is the fact that very often competing or conflicting design decisions in an educational setting are based on material from different academic courses. In the first example, the location of transverse bulkheads is driven by knowledge gained in the $P S D$ course while the affected propulsion equipment is considered in the $S P D$ course. The more specific details of the bulkhead's design are analyzed in the ship structures course. These details include configuration, volume and weight information vital to moving forward with the design. Similar cross-course conflicts are common and are a valuable part of the design process experience. 
The USCGA one-semester ship design, as stated above, involves significant aspects of both conceptual and preliminary design. Unfortunately, there is not time in one semester to make multiple trips around the entire design spiral that usually accompany these stages of design. Instead, week by week, decisions are being made that are somewhat irreversible. One could argue that this represents only one trip around the design spiral, but "just-in-time" learning unfortunately restricts designers to just this one revolution. The students have little time to revisit a previous design decision based upon knowledge gained later in the semester, but frequently find themselves moving backwards (or counter clockwise) before they can move forward (clockwise).

Compared to the USCGA serial design spiral approach to design, set-based design is likely a far more dependable way to create superior ship designs, even if multiple trips around the design spiral might otherwise have been possible. The NA\&ME instructors at USCGA have become the bridge in the design process between an educational setting that demands a single-trip design spiral approach and real-world evidence that set-based design is more appropriate. Specifically, each of the authors is an instructor for either the $P S D$, SS, or SPD course.

During the summer each year, the three instructors spend significant time meeting and discussing the pertinent design issues for the ship that will be addressed that fall. Specifically, major design conflicts (tradeoffs and/or compromises) that will arise between material and concepts from different courses are identified, albeit in an informal way. The three faculty then discuss options for resolving those conflicts in the design setting. The three faculty are also typically able to discuss the operational requirements, design options, and design drivers with USCG operational and engineering personnel who are actively working on the selected project. It is in this way that the faculty are integrating the content from the three courses. The result of this is that the instructors are able to tailor their classroom presentations based on summertime discussions such that a range of solutions to the design challenges of that day or week can be discussed with the students in the classroom. All of the above creates a significant increase in time and effort necessary for class preparation each summer, particularly when the type of ship changes from year to year.

During the semester, communication between the three faculty increases significantly as the students encounter design difficulties. The pace of each course ebbs and flows as the design progresses, and assignment due dates must constantly be adjusted in each course to manage student workload. When possible, all three faculty make themselves available to the cadets in the design laboratory even though the laboratory periods are technically only associated with the $P S D$ course. In fact, there are even times when all three instructors are circulating in the design laboratory at the same time. Instructors also use established links with USCG operators and engineers to help address difficult issues that arise.

Based upon cadet design team conversations with faculty (sometimes with 2 or 3 instructors at once), a wider range of design solutions can be considered than would otherwise be possible if the cadet teams were left on their own. A key point is that student interaction with faculty allows the students to see into the future of their classroom-based learning experience as a result of faculty guidance in the form of "you will learn in a few days that .." or "you don't know this 
yet, but your proposed design decision will create a problem with..." The strong and consistent communication between the three instructors and with the students allows for a wide range of approaches to individual design solutions. The student "view into the future" facilitated by the faculty effectively serves the purpose of more trips around the design spiral by the students. The combined effect of a wider range of possible solutions to design decisions and multiple considerations of the design of each particular ship system or component moves the USCGA ship design experience much closer to a set-based design than might be expected from the largely serial design approach that results from "just-in-time" learning. The three instructors serve as that bridge toward set-based design on a foundation of frequent and strong communication among themselves.

An additional benefit of laboratory design that is closely supported (both temporally and based on subject matter) by classroom instruction is that some of the common student-perceived disconnections between classroom principles and design applications are avoided. Sometimes on the same day cadets are seeing material presented in the classroom applied to decision in the laboratory. Also, the students see their instructors - who may have earlier presented a "double integral" explanation of a particular concept - walking into the laboratory and demonstrating a practical application of that material to the student ship design.

\section{Assessment}

The assessment of this design experience occurs as part of a three-tiered (course, program, and departmental) system of processes that exist within the Department of Engineering at USCGA (Colella, 2002 ${ }^{1}$ ). Metrics to evaluate success range from grades in the class (design specification submittals, exams, mid term design reviews, homework, papers, etc.) to a biannual program review that incorporates a comprehensive evaluation of program-level outcomes. At the conclusion of the senior year, exit interviews are conducted with each graduate that focus on program-level outcomes and program educational objectives. The final design presentation, conducted before a panel of industry, academic and professional experts serves as an important feedback mechanism on both the process and the quality of the results.

\section{Today's Demanding Environment}

As is evident in our discussion of the ship design experience at USCGA we consider it an essential component of our NA\&ME program. The NA\&ME program at USCGA is somewhat different than many engineering programs in that we know with relative certainty the likely future employment paths for our graduates. Because of this unique understanding, we have a great responsibility to the Coast Guard and to our students to prepare them for their future employment in service to our taxpaying nation. It is in this context that we pursue our ship design sequence following the guidance provided by the ABET Accreditation Criteria.

It is interesting in our case to reflect that the ABET emphasis on academic design experience is presumably motivated by a need for graduates to be prepared to do design work as practicing engineers. In contrast, in our program, the design sequence is very important because we know our graduates will likely experience hands on design work only in an academic environment. Not all of our Naval Architecture and Marine Engineering graduates pursue an engineering 
career path, but all of them serve on active duty in the Coast Guard where their technical knowledge is a definite asset. The majority of our Naval Architecture and Marine Engineering graduates do choose to pursue an engineering career, and they spend the first few years after graduation gaining shipboard engineering operational experience. After that they typically go to a shoreside ship maintenance support office or to a Coast Guard Marine Safety Office. In these shore assignments they serve as junior engineers interacting with shipboard personnel and shipyards with the responsibility for the safety, maintenance, and repair of ship and boat structures, machinery, and equipment. Following this they will typically be sent to graduate school by the Coast Guard to earn a Masters Degree in Naval Architecture and Marine Engineering or in Mechanical Engineering. This is then followed by a progression of increasingly more responsible positions in the acquisition, operation, and maintenance of Coast Guard ships and boats, and in the writing and enforcement of U. S. and international maritime safety regulations. In today's Coast Guard this progression rarely if ever includes an opportunity to be actively involved in design work.

The Coast Guard, like most other U. S. government agencies, has sought to increase the ratio of operational personnel to support personnel and to increase economic efficiency by relying more and more on contractors for engineering and technical support. This is seen in the Coast Guard Deepwater System acquisition program where one prime contractor is designing and building multiple classes of Coast Guard ships, and the price tag is in the $\$ 20$ billion dollar range. This is also seen in the maritime safety arena where the Coast Guard accepts commercial vessel safety evaluations performed the American Bureau of Shipping and other international ship classification societies. It is the graduates of the Coast Guard Academy that must write and administer the contracts and evaluate the performance of the contractors and the classification societies. It is also our graduates that represent the U. S. in the drafting and negotiation of international maritime safety regulations.

Our graduates do rapidly gain practical engineering experience, and this experience, combined with excellent graduate school programs, provides an excellent professional naval engineering workforce for the Coast Guard. In times past there were many more opportunities for our graduates to gain direct experience in the design, construction, and inspection of ships and boats. Today many of those opportunities no longer are available to our graduates, but their ultimate responsibilities in these areas have not decreased. This increases the importance of our academic programs particularly in the areas such as ship design. It is sobering to recognize that our graduates will be responsible for billions of dollars worth of ship design and construction and for maritime safety and environmental protection around the world. We believe the lessons they learn in our ship design sequence will help them do these jobs well.

\section{Wrap Up}

The combination of a broad based, highly integrated subject area, and an extremely demanding military academy setting require USCGA NA\&ME faculty to work as a team in coordinating and managing an effective capstone design project. At USCGA, three faculty, teaching three different courses, have developed a semester-long design project approach that incorporates principles and practices from each subject area. The students have remarked that they have a greater understanding and appreciation of the discipline and they feel that what they have learned 
will help them immensely in their careers. Comprehensive course and program assessments indicate that graduates are entering the field well prepared and motivated to learn more.

Today's environment demands that the leaders of our technologically-based Coast Guard have the necessary tools to be effective protectors of the nation's homeland and responsible stewards of the American taxpayer's dollar. With billion dollar projects presently underway to recapitalize the Coast Guard's operational hardware, it is imperative that each graduate have as much "real world" experience as humanly possible. The people of this great nation deserve nothing less.

The authors are more than willing to provide further documentation regarding course content, design project details, and/or assessment information to any interested parties.

\section{Bibliography}

1. Colella, K.J., "The Implementation of an Effective System of Assessment in the Engineering Department at the United States Coast Guard Academy," Frontiers in Education, Boston, MA, 2002.

2. $\quad$ Evans, J.H., "Basic Design Concepts,” ASNE Journal, November 1959.

3. Lamb, T., ed., Ship Design and Construction, Society of Naval Architects and Marine Engineers, 2003.

4. Taggart, R., ed., Ship Design and Construction, Society of Naval Architects and Marine Engineers, 1980. 